\title{
Carbon conversion and metabolic rate in two marine sponges
}

\author{
M. Koopmans • P. van Rijswijk • D. Martens • \\ T. A. Egorova-Zachernyuk $\cdot$ J. J. Middelburg $\cdot$ \\ R. H. Wijffels
}

Received: 9 November 2009/Accepted: 24 August 2010/Published online: 7 September 2010

(C) The Author(s) 2010. This article is published with open access at Springerlink.com

\begin{abstract}
The carbon metabolism of two marine sponges, Haliclona oculata and Dysidea avara, has been studied using a ${ }^{13} \mathrm{C}$ isotope pulse-chase approach. The sponges were fed ${ }^{13} \mathrm{C}$-labeled diatoms (Skeletonema costatum) for $8 \mathrm{~h}$ and they took up between 75 and $85 \%$. At different times, sponges were sampled for total ${ }^{13} \mathrm{C}$ enrichment, and fatty acid (FA) composition and ${ }^{13} \mathrm{C}$ enrichment. Algal biomarkers present in the sponges were highly labeled after feeding but their labeling levels decreased until none was left 10 days after enrichment. The sponge-specific FAs incorporated ${ }^{13} \mathrm{C}$ label already during the first day and the amount of ${ }^{13} \mathrm{C}$ label inside these FAs kept increasing until 3 weeks after labeling. The algal-derived carbon captured by the sponges during the 8 -h feeding period was thus partly respired and partly metabolized during the weeks following. Apparently, sponges are able to capture enough food during short periods to sustain longer-term
\end{abstract}

Communicated by H.O. Pörtner.

M. Koopmans · D. Martens $(\bowtie) \cdot$ R. H. Wijffels

Department of Agrotechnology and Food Sciences, Bioprocess Engineering group, Wageningen University, P.O. 8129, 6700 EV Wageningen, The Netherlands e-mail: dirk.martens@wur.nl

P. van Rijswijk · J. J. Middelburg

Netherlands Institute of Ecology (NIOO-KNAW),

P.O. Box 140, 4400 AC Yerseke, The Netherlands

\section{J. J. Middelburg}

Faculty of Geosciences, Utrecht University,

P.O. Box 80.021, 3508 TA Utrecht, The Netherlands

T. A. Egorova-Zachernyuk

Protein Labelling Innovation (PLI), BioScience Park,

Archimedesweg 27, 2333 CM Leiden, The Netherlands metabolism. The change of carbon metabolic rate of fatty acid synthesis due to mechanical damage of sponge tissue was studied by feeding sponges with ${ }^{13} \mathrm{C}$ isotope-labeled diatom (Pheaodactylum tricornutum) either after or before damaging and tracing back the ${ }^{13} \mathrm{C}$ content in the damaged and healthy tissue. The filtration and respiration in both sponges responded quickly to damage. The rate of respiration in $\mathrm{H}$. oculata reduced immediately after damage, but returned to its initial level after $6 \mathrm{~h}$. The ${ }^{13} \mathrm{C}$ data revealed that $H$. oculata has a higher metabolic rate in the tips where growth occurs compared to the rest of the tissue and that the metabolic rate is increased after damage of the tissue. For D. avara, no differences were found between damaged and non-damaged tissue. However, the filtration rate decreased directly after damage.

\section{Introduction}

Sponges are known for their capacity to produce bioactive secondary metabolites. However, no sustainable production techniques have been developed yet to obtain sufficient quantities of these potential pharmaceuticals. In order to develop such techniques and to maximize productivity, we need to obtain a better understanding of feeding and metabolic rates in sponges. Sponges are heterotrophic organisms and pump large amounts of water through their body from which particles are filtered (Bergquist 1978). How and at which rate these particles are metabolized in sponges has not been studied widely (Schmidt 1970; Hahn et al. 1988). One of the problems in studying sponge metabolism is that particles filtered out of the water are not immediately metabolized. To understand sponge metabolism, it is necessary to be able to distinguish whether a compound is part of the taken food particles or of the sponge tissue. 
This problem can be solved by looking at the metabolism of biomarkers, which are compounds only present in the sponge and not in the food. In a previous study, we found several fatty acids that could serve as a biomarker for sponges (Koopmans 2009). Among aquatic animals, sponges are specified by the greatest diversity of sterols and fatty acids (FAs), which have an unusual and sometimes unique structure (Litchfield et al. 1976; Thiel et al. 1999; Rod'kina 2005). Sponges contain large quantities of $\mathrm{C}_{22}-\mathrm{C}_{30}$ fatty acids with branched and odd-chains and hydroxyl-acids (Bergquist et al. 1984; Christie et al. 1992; Thiel et al. 1999; Nechev et al. 2002; Rod'kina et al. 2003). These very long-chain fatty acids are sometimes called 'demospongic acids' (Rod'kina 2005). Fatty acids are very diverse in structure and chain length, and some are unique for certain organisms. Consequently, many researchers have used FAs and combinations of FAs as biomarkers for algal or bacterial biomass (Dunstan et al. 1994; Boschker and Middelburg 2002; Kharlamenko et al. 2008). One of the problems we encountered in our previous study (Koopmans 2009) is that some of the demospongic acids were also found in suspended particles, implying either that these demospongic acids are not unique or that sponge detritus contributes substantially to suspended particle organic matter pools. This non-uniqueness of putative biomarkers is a common problem in organic geochemistry and microbial ecology (Boschker and Middelburg 2002). However, this can be solved by using isotopically labeled single algae species as a food source. ${ }^{13} \mathrm{C}$ label appearing in sponge-specific fatty acids, which are not present in the added algae, can then be attributed to metabolism of the sponge.

Sponges possess an active homologation enzyme system using short-chain fatty acid precursors largely derived from exogenous sources as substrate (Djerassi and Lam 1991). Therefore, the composition of sponge FAs is probably related to the composition of food FAs and symbionts. Biosynthesis of fatty acids has been studied before in different sponges by using ${ }^{14} \mathrm{C}$-label (Raederstorff et al. 1987; Hahn et al. 1988). In Aplysina fistularis, it was found that 22MeC28:2(5,9) was elongated from 10MeC16:0 to 22MeC28:0 and then further desaturated (Raederstorff et al. 1987). Hahn et al. (1988) elucidated the biosynthesis of two common long-chain 'demospongic acids' in the sponge Microciona prolifera. They found that C14:0 was first elongated to $\mathrm{C} 26: 0$, which was then further desaturated to form C26:2(5,9). Moreover, Hahn et al. (1988) showed that $\mathrm{C} 26: 3(5,9,19)$ had an exogenous palmitoleic acid (C16:1(9)) as precursor. Recently, a ${ }^{13} \mathrm{C}$ labeling approach was used to study sponge carbon uptake from different food sources in a bacterial sponge in its natural habitat (de Goey et al. 2008). Fast uptake and conversion of food sources was found in the sponge and its symbionts.
However, how long it takes for ${ }^{13} \mathrm{C}$ label to be incorporated into the longer-chain FAs was not studied (de Goey et al. 2008).

Damaged sponge tissue regenerates at higher rates than the corresponding growth rates of the same sponge species (Ayling 1983; De Caralt et al. 2008). The rate of metabolism associated with regeneration and whether more energy is allocated toward the damaged tissue is not known.

The aim of this paper is to get a better understanding of food uptake and metabolism of sponges and to find the effect of damage on sponge metabolism and growth. Sponges were fed ${ }^{13} \mathrm{C}$-labeled diatoms and label appearance and eventual loss in (sponge) fatty acids were followed over time. In addition, ${ }^{13} \mathrm{C}$-label incorporation into sponge fatty acids was also used to assess the effect of damaged sponge tissue on metabolic rate of the sponge. Different types of sponges were used in this study. Haliclona oculata occurs abundantly in the Oosterschelde, the Netherlands in temperatures ranging from $2-23^{\circ} \mathrm{C}$. It is a finger sponge attached at one base, containing many spicules to build their strong skeleton. Dysidea avara is a widely distributed sponge species in the Mediterranean (Uriz et al. 1992), where temperature varies between $12-25^{\circ} \mathrm{C}$. It is an encrusting sponge that can be found on rocky substrata. Also lobulated masses can be found. The skeleton is a meshwork of sponging fibers without spicules (Ribes et al. 1999), which makes it a more fragile sponge than H. oculata.

\section{Materials and methods}

Feeding experiment for metabolic rate

The sponge species used were Haliclona oculata and Dysidea avara. These sponges are not related and live in different habitats. $H$. oculata is a finger sponge and occurs widely in the Oosterschelde, a tidal inlet in the Netherlands (Lokkersnol, $51^{\circ} 38^{\prime} 58.07^{\prime \prime} \mathrm{N}, 3^{\circ} 53^{\prime} 5.11^{\prime \prime} \mathrm{E}$ ), and grows attached to solid surfaces such as oyster shells. Dysidea avara is an encrusting sponge and occurs abundantly in the Mediterranean, Spain (Cala Montgo, $42^{\circ} 06^{\prime} 50.33^{\prime \prime} \mathrm{N}$, $\left.3^{\circ} 10^{\prime} 02 \cdot 10^{\prime \prime} \mathrm{E}\right)$.

For metabolic rate studies, 27 sponge specimen of Haliclona oculata were collected on August 13, 2007, by scuba diving in the Oosterschelde at $\sim 13 \mathrm{~m}$ depth, water temperature $20^{\circ} \mathrm{C}$. Sponges were transported to the laboratory in aerated boxes in their natural seawater and placed within $2 \mathrm{~h}$ in three aquaria (water volume approximately 80 1) with continuous flowing natural seawater directly pumped from the Oosterschelde. On January 21, 2008, 18 sponge specimen of Dysidea avara were collected in the Mediterranean at $\sim 8 \mathrm{~m}$ depth, water-temperature $14^{\circ} \mathrm{C}$. 
Sponges were transported to two aquaria (water volume approximately 100 l) containing natural seawater close to the sea within $1 \mathrm{~h}$ after collection.

Haliclona oculata specimens were kept for 1 week in the new environment prior to the pulse labeling for acclimation. After 1 week, the sponges were fed with $300 \mathrm{ml}$ of living ${ }^{13}$ C-labeled Skeletonema costatum per aquarium. The diatom $S$. costatum was cultured at $16^{\circ} \mathrm{C}$ in $\mathrm{F} 2$ medium in 61 artificial seawater containing $25 \%{ }^{13} \mathrm{C}$-labeled $\mathrm{NaHCO}_{3}$. The culture was centrifuged at $1,000^{*} g$ and washed 3 times with filtered unlabeled seawater to remove any remaining ${ }^{13} \mathrm{C}$ label after which they were diluted to 17,000 cells per $\mathrm{ml}$ to feed the sponges. Three samples of $1 \mathrm{ml}$ were taken from the $S$. costatum culture to analyze algal fatty acids and ${ }^{13} \mathrm{C}$ content. During labeling, the continuous flowing seawater was stopped and pumps were used to mix the seawater in the aquaria to prevent cells from settling on the bottom. After the pulse of ${ }^{13} \mathrm{C}$-labeled cells, we counted the cells every hour to determine sponge filtration rate. After $8 \mathrm{~h}$, most cells were filtered out and the continuously flowing seawater was turned on again. Whole sponges were sampled from each aquarium at day 0 (before feeding), after $8 \mathrm{~h}$ (directly after labeling), and at days 1, 2, 3, 7, 10, 14, and 21. The sampled sponges were frozen in liquid nitrogen and stored at $-80^{\circ} \mathrm{C}$ until freeze-drying for $24 \mathrm{~h}$.

Dysidea avara specimens collected from the field were immediately fed with $300 \mathrm{ml}$ Skeletonema costatum culture per aquarium. Sponge filtration was assessed by sampling particulate matter after $1 \mathrm{~h}$ and at the end of the feeding by analysis of particulate organic ${ }^{13} \mathrm{C}$ content. Sponge feeding in the aquaria lasted for $8 \mathrm{~h}$ and afterward, the sponges were placed back into the sea at the site of collection. At day 0 (before feeding), after $8 \mathrm{~h}$ (directly after feeding), and at days $1,2,4$, and 8 three $(n=3)$ sponge specimen were sampled for further analysis. The collected specimen were frozen on dry ice and in this way transported to the laboratory. The sponges were stored at $-80^{\circ} \mathrm{C}$ until freeze-drying for $24 \mathrm{~h}$.

Feeding experiment with damaged sponges

\footnotetext{
${ }^{13} \mathrm{C}$ labeling experiments with damaged Haliclona oculata were done in situ in the Netherlands on September 26, 2007, water temperature $17^{\circ} \mathrm{C}$. A platform was placed at the study site and 42 concrete pavement tiles $(30-\mathrm{cm} \times$ $30-\mathrm{cm}$ ) were placed on top of the platform (Koopmans and Wijffels 2008). On every tile, a sponge specimen was attached. Twelve specimens were used in this experiment. These specimens had been attached to the tiles on the platform already for several months. The ${ }^{13} \mathrm{C}$ labeling experiments with Dysidea avara were done in situ in Spain on January 22,2008 , with a water temperature of $14^{\circ} \mathrm{C}$. On 21 January, 12 D. avara specimens were collected with
}

their rocky substrate. The substrate was glued to tiles located close to the place of collection.

The uniformly ${ }^{13} \mathrm{C}$ (I.E. 99.5\%)-labeled biomass of Pheaodactylum tricornutum in lyophilized form was purchased from Protein Labelling Innovation (PLI), the Netherlands. The sponges on the platform were fed with this ${ }^{13} \mathrm{C}$-labeled biomass of $P$. tricornutum. A suspension containing $22.5 \mathrm{mg} P$. tricornutum in $15 \mathrm{ml}$ of seawater was fed to the sponges for $25 \mathrm{~min}$. For the in situ experiments, special experimental chambers made of polyvinylchloride (PVC) with 3,800 ml volume were developed. The chamber had an opening underneath to completely cover the sponge. The chamber was placed over the sponge, and by using elastic bands the chamber could easily be attached to the tiles. The chamber had two connections, one to connect an oxygen probe and a small sampling tube for adding the $P$. tricornutum solution. A magnetic stirrer inside the chamber continuously mixed the water inside to prevent particles from settling and to equalize oxygen distribution. Oxygen concentrations were measured using an Oxi 340i handheld oxygen meters (WTW, Weilheim, Germany). The oxygen concentration inside a chamber was logged every $10 \mathrm{~s}$. The meter connected to the probe was in a waterproof box and taken underwater. Feeding experiments lasted for $25 \mathrm{~min}$, to minimize the effect of oxygen depletion. In total, we used 3 experimental chambers. Since the maximal dive-time was $60 \mathrm{~min}$, we could feed six sponges during one dive.

The finger sponge $H$. oculata was damaged using scissors, and all tips of the sponge were cutoff. D. avara was damaged by scraping of sponge tissue on one side of the sponge, keeping more than half of the sponge undamaged. To find differences between sponges that were damaged and not damaged, we used 12 sponge individuals, which were divided into four groups that were treated as described in Table 1. Thus, for each strategy, 3 sponge specimens were used. In this way, we could measure differences in uptake rate due to damage. One week after feeding, the sponges were collected. After collection, we separated the damaged tissue and the healthy part of the sponge body to be able to find differences in amount of ${ }^{13} \mathrm{C}$ label in the different parts of the sponge. The collected specimen were

Table 1 Feeding strategies for both Haliclona oculata and Dysidea avara

\begin{tabular}{lll}
\hline Damage & Feeding/Labeling & Remark \\
\hline No & Without damage & Reference samples \\
Yes & Before damage & \\
Yes & Immediate after & \\
& damage & \\
Yes & 6 or $24 \mathrm{~h}$ after & $6 \mathrm{~h}$ for H. oculata, \\
& damage & $24 \mathrm{~h}$ for D. avara \\
\hline
\end{tabular}


frozen on dry ice and in this way transported to the laboratory in $2 \mathrm{~h}$. The sponges were stored at $-80^{\circ} \mathrm{C}$ until freeze-drying for $24 \mathrm{~h}$. The dry sponges were grinded with mortar and pestle before further usage.

Total carbon and ${ }^{13} \mathrm{C}$ content analysis

The freeze-dried sponges were grinded with mortar and pestle before further usage. The carbon content of all sponge individuals was measured using a Fisons NA 2500 element analyzer with auto sampler and Haysep-Q column 80-100 mesh I.D. $2 \mathrm{~mm}$ (Nieuwenhuize et al. 1994). In short, the dried sample was flash combusted in an oxygenrich environment, and the generated $\mathrm{CO}_{2}$ and $\mathrm{N}_{2}$ were separated on a GC column and detected using a thermal conductivity detector. Moreover, the $\mathrm{CO}_{2}$ released was then transferred via a Conflo II interface to and isotoperatio mass spectrometry to measure the carbon isotopic composition (EA-IRMS) (Middelburg et al. 2000).

Fatty acid and ${ }^{13} \mathrm{C}$ analysis

About $100 \mathrm{mg}$ sponge dry weight was used for lipid extraction using an adjusted Bligh and Dyer method (see also (Boschker et al. 1999; Middelburg et al. 2000). The total lipid fraction was derivatized by mild alkaline methanolysis to obtain fatty acid methyl esters (FAME). Both C12:0 and C19:0 were used as internal FAME standards. Identification of the fatty acids was done using equivalent chain length data with known standards measured on a non-polar column. Additional identification was done using GC-MS. Carbon isotopic composition of individual FAME was determined with a gas-chromatograph combustion-interface isotoperatio mass spectrometer (GC-c-IRMS); a HP G1530 GC (Hewlett Packard) connected to Delta-plus IRMS via a typeIII combustion interface from Thermo Finnigan (Bremen). Helium was used as a carrier gas (150 kPa) with an apolar column (Hewlett-Packard HP-5MS, $60 \mathrm{~m} * 0.32 \mathrm{~mm}$ $* 0.25 \mu \mathrm{m}$ ). The column was kept at $70^{\circ} \mathrm{C}$ for $2 \mathrm{~min}$, then temperature was programed from 70 to $150^{\circ} \mathrm{C}$ at $20^{\circ} \mathrm{C}$ $\mathrm{min}^{-1}$, subsequently from 150 to $290^{\circ} \mathrm{C}$ at $3^{\circ} \mathrm{C} \min ^{-1}$ and from $290^{\circ} \mathrm{C}$ to $325^{\circ} \mathrm{C}$ at $5^{\circ} \mathrm{C} \mathrm{min}^{-1}$, temperature was kept at $325^{\circ} \mathrm{C}$ for $11 \mathrm{~min}$. Fatty acid concentrations were determined by area correction according to the C19:0 internal standard. Stable carbon isotope ratios $\left({ }^{13} \mathrm{C} /{ }^{12} \mathrm{C}\right)$ for individual FA were calculated from FAME data by correcting for the one carbon atom in the methyl group that was added during derivatization (Middelburg et al. 2000).

Enrichment calculation

High-precision isotope ratios were determined as the relative difference in ${ }^{13} \mathrm{C} /{ }^{12} \mathrm{C}$ of a sample and the international standard for carbon of Vienna PeeDeeBelemnite (PDB). Isotope measurements are usually given in the $\delta$-notation (in part per thousand) calculated using the following equation:

$\delta^{13} \mathrm{C}(\%)=\left(\mathrm{R}_{\text {sample }} / \mathrm{R}_{\mathrm{PDB}}-1\right) \times 1000$

The absolute amounts of ${ }^{13} \mathrm{C}$-label $\left(\mu \mathrm{g}{ }^{13} \mathrm{Cg} \mathrm{dw}^{-1}\right)$ in FA can be calculated from the concentration $\mu \mathrm{g} \mathrm{FA} \mathrm{g} \mathrm{dw}^{-1}$ (C) and the increase in the fraction ${ }^{13} \mathrm{C}$ after labeling $\left(\mathrm{F}^{13}\right)$ relative to the control $\left(\mathrm{F}_{\mathrm{c}}^{13}\right)$ :

${ }^{13} \mathrm{C}=\left(\mathrm{F}^{13}-\mathrm{F}_{\mathrm{c}}^{13}\right) * \mathrm{C}$

where

$\mathrm{F}^{13}=\mathrm{R} /(\mathrm{R}+1)$ and $\mathrm{R}=\left(\delta^{13} \mathrm{C} / 1000+1\right) \times \mathrm{R}_{\mathrm{PDB}}$

Cell count

A Beckman coulter counter was used to count the cells during the pulse feeding of Haliclona oculata. Samples of $20 \mathrm{ml}$ were taken after $0,0.5,1,2,3,4,5,6$, and $8 \mathrm{~h}$ from each aquarium. Only cells larger than 4 micron were counted.

Respiration rate

Respiration rates were measured for $H$. oculata at days -4 , $-3,-2,-1,0,1,2,7$, and 14. Respiration experiments were performed in polyvinylchloride (PVC) experimental chambers with a volume of $765 \mathrm{ml}$ and with an opening underneath to completely cover the sponge. Chambers were placed over the sponge and thus the sponge was not affected. An oxygen probe was connected to each chamber. A magnetic stirrer inside chambers continuously mixed the water inside to prevent particles from settling and to homogenize oxygen distribution. $\mathrm{O}_{2}$ concentrations were measured and logged every $10 \mathrm{~s}$ using two Oxi 340i handheld oxygen meters (WTW, Weilheim, Germany). Experiments lasted for $15 \mathrm{~min}$, to minimize the effect of oxygen depletion on respiration rates.

\section{Results and discussion}

First, the results to determine metabolic rate are discussed for both Haliclona oculata and Dysidea avara, after which the damage experiments are discussed for both species.

Carbon metabolic rate

Both marine sponge species were fed ${ }^{13} \mathrm{C}$-labeled living diatoms $\left(4\right.$ atom $\left.\%{ }^{13} \mathrm{C}\right)$, and carbon uptake, assimilation, and conversion were followed over time. Dysidea avara from the Mediterranean, Spain, retained less ${ }^{13} \mathrm{C}$ than 
Haliclona oculata from the Oosterschelde, the Netherlands, which may be partly the result of different feeding strategies and experimental procedures for both sponges. $H$. oculata was given 1 week to readjust from field to laboratory conditions. Labeling took place using actively growing Skeletonema costatum cells and the experiment lasted for 3 weeks. For D. avara, the experiment only lasted 1 week. And the feeding took place immediately after collection in a stirred non-flushed aquarium with live diatoms that were stored for 3 days. After the 8-h feeding period, D. avara sponges were placed back in their natural habitat. We will focus our discussion on the results for H. oculata because this experiment lasted longer, more ${ }^{13} \mathrm{C}$ uptake occurred, and the diatoms provided were actively growing.

\section{Haliclona oculata}

During labeling, water samples were taken to follow diatom uptake. For the H. oculata experiment, we were able to immediately analyze the water samples by counting cells (Fig. 1). This allowed us to optimize experimental procedures and in particular the feeding period. More than $75 \%$ of the diatoms were filtered by the sponges within $8 \mathrm{~h}$. Moreover, it also allowed estimating a filtration rate $\left(\mathrm{F} ; \mathrm{l} \mathrm{h}^{-1}\right.$ sponge $^{-1}$ ) using the next equation:

$C(t)=C(0) e^{\frac{F}{V} t}$

where $\mathrm{C}$ represents the concentration of diatoms, $\mathrm{V}$ is the volume of water per sponge (1 sponge ${ }^{-1}$ ) and $t$ is time (h). The filtration rate based on the uptake of $S$. costatum cells found for $H$. oculata was $1.7 \mathrm{l} \mathrm{h}^{-1}$ sponge $^{-1}$. This is an average value for 12 sponge individuals. This is somewhat lower than the value of $3.41 \mathrm{~h}^{-1}$ sponge $^{-1}$ found for H. oculata in its natural habitat (Koopmans et al. 2009). This may be due to the transfer to the aquaria causing the sponge to filter at a lower rate. Total ${ }^{13} \mathrm{C}$ enrichment of the

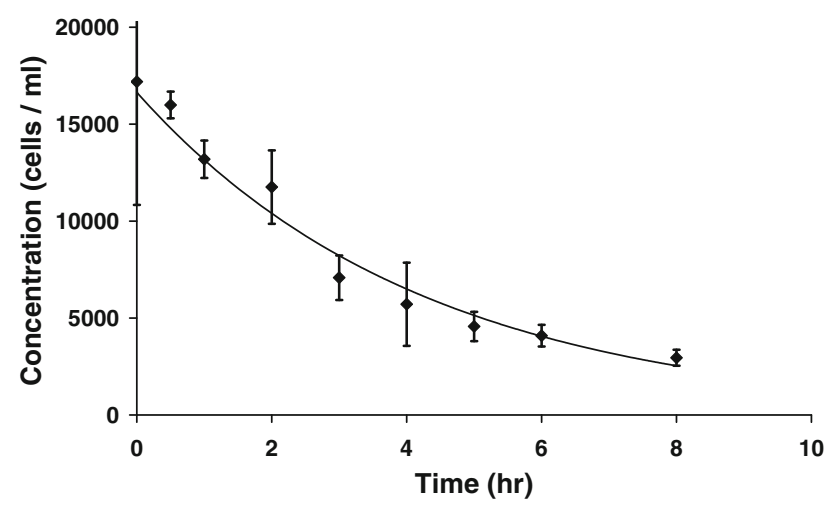

Fig. 1 Skeletonema costatum cell number decrease during pulse label feeding of Haliclona oculata. Average cell count \pm standard deviation of triplicate measurements of all aquaria are shown sponge specimen was followed in time (Fig. 2a). Most enrichment was found immediately after labeling and up to day 1 , after that ${ }^{13} \mathrm{C}$ content decreased gradually. Variability was high during the initial period (till day 1 ), which may be due to the difference in filtration activity by sponge individuals. Three different sponges, one from each aquarium, were collected each sampling, thus when a sponge did or did not filter a lot of material during the 8-h feeding period this had major consequences for ${ }^{13} \mathrm{C}$ acquisition. After the first day, the ${ }^{13} \mathrm{C}$ content decreased and thus $H$. oculata started to excrete or respire acquired carbon. This decrease was initially rapid and then more gradual. This initial rapid decrease may be due to the loss of diatom cells or rapid respiration of part of the ${ }^{13} \mathrm{C}$. The subsequent gradual decrease of ${ }^{13} \mathrm{C}$ label in the sponge could be due to slow turnover of assimilated carbon. The decrease in ${ }^{13} \mathrm{C}$ was expected as we found in our previous work that about $10 \%$ of carbon acquired was used for biomass assimilation and over 90\% was used for respiration (Koopmans et al. 2009). After 3 weeks, still $22.3 \%$ of the carbon acquired within the 8 -h pulse labeling period was inside $H$. oculata. Thus, we can distinguish between an initial phase with rapid ${ }^{13} \mathrm{C}$ loss possibly due to direct loss of diatoms or rapid respiration and second phase with a slower ${ }^{13} \mathrm{C}$ loss in which ${ }^{13} \mathrm{C}$ label due to a slow turnover of assimilated ${ }^{13} \mathrm{C}$. Tracing ${ }^{13} \mathrm{C}$ in $\mathrm{FA}$ will be instructive to further elucidate this.

For the $H$. oculata sponges, we also measured respiration rate several times. We found a slight decrease in respiration rate during the first week after collection (during acclimatization period) from 96.2 to $86.9 \mu \mathrm{mol} \mathrm{O}_{2} \mathrm{~h}^{-1} \mathrm{~g}$ $\mathrm{dw}^{-1}$, which qualitatively agrees with the somewhat low filtration rates in the aquaria. Two weeks after feeding the respiration rate was $82.5 \mu \mathrm{mol} \mathrm{O}_{2} \mathrm{~h}^{-1} \mathrm{~g} \mathrm{dw}^{-1}$. These values are all within the range found for this species in its natural habitat (Koopmans et al. 2009), indicating that they were performing well in the aquaria. A respiration rate of $86.9 \mu \mathrm{mol} \mathrm{O}_{2} \mathrm{~h}^{-1} \mathrm{~g} \mathrm{dw}^{-1}$ corresponds to a carbon usage for respiration of $65.2 \mu \mathrm{mol} \mathrm{C} \mathrm{h}^{-1} \mathrm{~g} \mathrm{dw}^{-1}$, assuming a respiratory quotient of $0.75 \mu \mathrm{mol} \mathrm{C} / \mu \mathrm{mol} \mathrm{O}_{2}$ (Hatcher

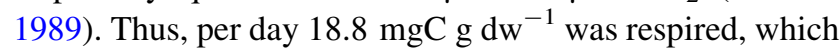
is in agreement with the decrease of ${ }^{13} \mathrm{C}$ (Fig. 2).

\section{Fatty acid enrichment}

The enrichment of ${ }^{13} \mathrm{C}$ in individual fatty acids of sponges was measured, and total quantity of label in FA is shown in Fig. 2b. Note that the $y$-axis is in $\mu g{ }^{13} \mathrm{C}$ per gram dry weight and in Fig. 2a this is in milligram ${ }^{13} \mathrm{C}$ per gram dry weight. Thus, only $10 \%$ of the incorporated ${ }^{13} \mathrm{C}$ were recovered in the form of FAs. After 3 weeks, about $7.6 \%$ of the FAs labeled after the 8 -h pulse were still present in the form of FAs (Fig. 2b). This is about 3 times less than we 

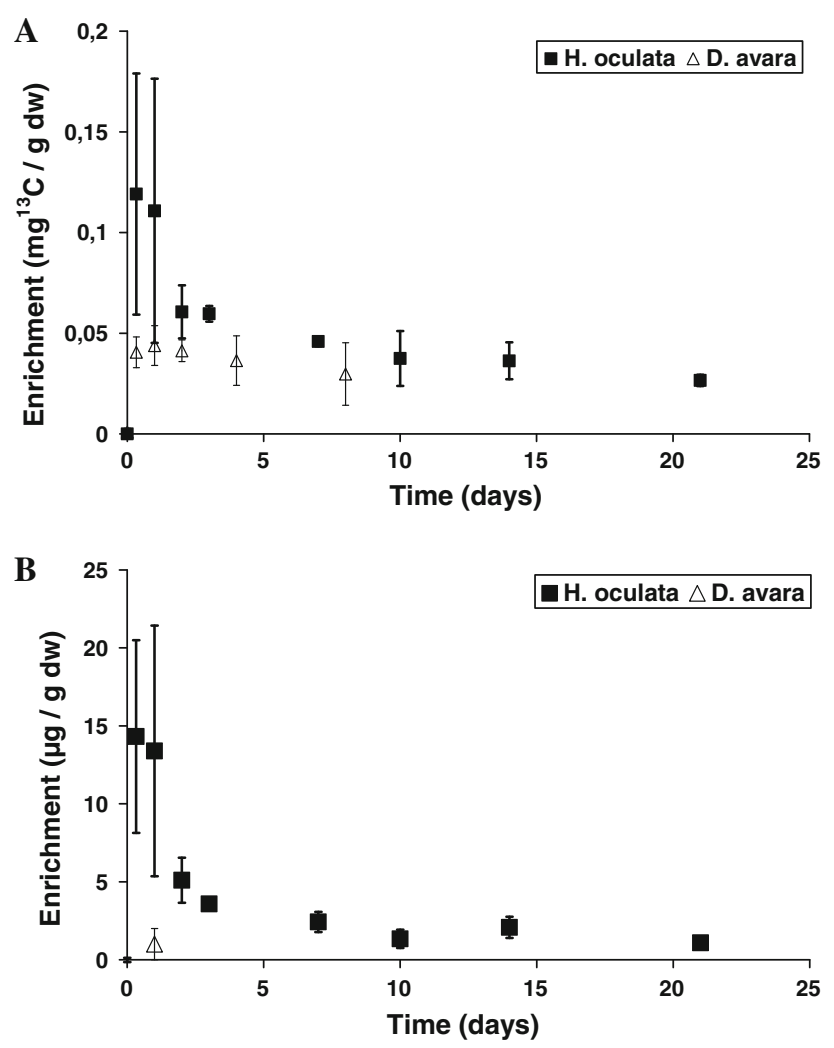

Fig. 2 Total ${ }^{13} \mathrm{C}$ enrichment (a) and total fatty acid enrichment (b) in the whole sponge for both Haliclona oculata and Dysidea avara

found for total carbon (22.3\%; Fig. 2a). Thus, fatty acids were either excreted faster or respired more than other organic compounds to obtain energy.

The ${ }^{13} \mathrm{C}$ content of specific fatty acids can be used to assess the fate of algal material and the metabolism of sponge fatty acids. Table 2 shows the percentage of the major fatty acids in the diatom used as food and in the two sponges. For H. oculata, we found some large sterol peaks at the end of the chromatogram, the major one could be attributed to campesterol ((24)-ergost-5-en-3beta-ol). The FAs C14:0, $\mathrm{C} 16: 3 \omega 4, \mathrm{C} 16: 1 \omega 7, \mathrm{C} 16: 0, \mathrm{C} 20: 5 \omega 3$ have high concentrations in the diatom cultured and fed to the sponges and have rather low concentrations in the sponges. These FAs with high concentrations in diatoms and low concentrations in sponges can be used to follow how fast diatom carbon was metabolized by the sponges. Similarly, a number of FA were not found in diatom material added and were present in the sponges and these can be used to trace formation and transformation of FA by sponges. However, some of these sponge FAs may in fact reflect prokaryotic symbionts (branched FA such as iC17:0 and aiC17:0).

Figure 3 shows the absolute ${ }^{13} \mathrm{C}$ content for the feed biomarkers per $1 \mathrm{ml} S$. costatum culture. The diatoms added were alive and not axenic to mimic natural conditions as much as possible. Therefore, some bacterial-
Table 2 Major fatty acids present in the diatom used for feeding and the sponges used

\begin{tabular}{|c|c|c|c|}
\hline Fatty acid & $\begin{array}{l}\text { Mass \% in } \\
\text { Skeletonema } \\
\text { costatum } \\
\text { (diatom) }\end{array}$ & $\begin{array}{l}\text { Mass\% in } \\
\text { Haliclona } \\
\text { oculata } \\
\text { (sponge) }\end{array}$ & $\begin{array}{l}\text { Mass\% in } \\
\text { Dysidea } \\
\text { avara } \\
\text { (sponge) }\end{array}$ \\
\hline C14:0 & 15.72 & 0.28 & 0.60 \\
\hline iC16:0 & 3.21 & 0.55 & 1.32 \\
\hline $\mathrm{C} 16: 3 \omega 4$ & 7.76 & 0.05 & 0.79 \\
\hline $\mathrm{C} 16: 1 \omega 7 \mathrm{c}$ & 26.64 & 1.61 & 0.93 \\
\hline C16:0 & 15.18 & 3.08 & 2.84 \\
\hline iC17:0 & & 0.52 & 1.19 \\
\hline aiC17:0 & & 0.51 & 1.17 \\
\hline $\mathrm{C} 18: 4 \omega 3$ & 3.83 & 0.24 & 1.20 \\
\hline C18:1w7 & 0.38 & 2.40 & 2.90 \\
\hline C20:4w6 & & 2.11 & 3.00 \\
\hline $\mathrm{C} 20: 5 \omega 3$ & 6.55 & 2.30 & 1.47 \\
\hline C20:1(13) & & 0.11 & 5.27 \\
\hline C22:6w3 & 1.51 & 6.41 & 3.49 \\
\hline C22:1(15) & 0.41 & & 8.21 \\
\hline aiC23:0 & & & 5.69 \\
\hline C24:1(17) & & 2.53 & 2.19 \\
\hline $\mathrm{C} 25: 2(5,9)$ & & & 2.98 \\
\hline $\mathrm{C} 26: 3(5,9,19)$ & & 5.66 & 9.51 \\
\hline $\mathrm{C} 26: 2(5,9)$ & & 10.18 & 6.68 \\
\hline $\mathrm{C} 28: 3(5,9,21)$ & & 11.41 & \\
\hline Campesterol & & 17.15 & \\
\hline
\end{tabular}

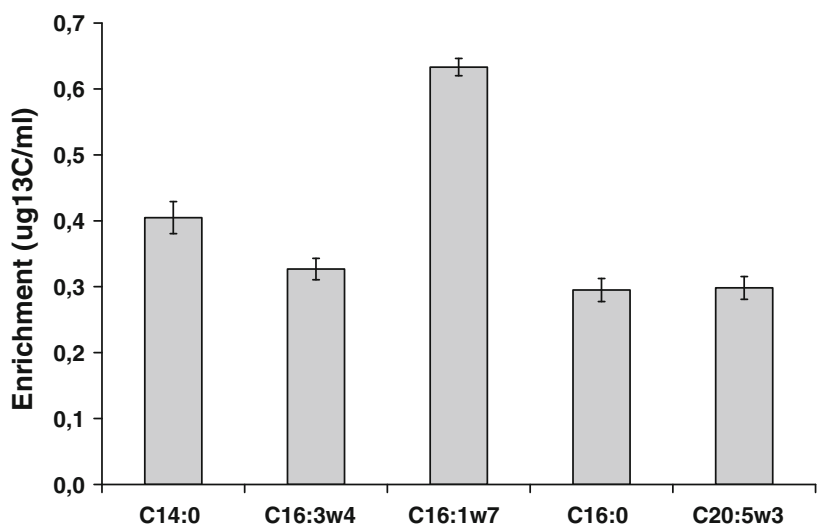

Fig. $3{ }^{13} \mathrm{C}$ Enrichment of fatty acids in Skeletonema costatum feed

derived FAs were present in the diatoms (Table 2). It is shown that most ${ }^{13} \mathrm{C}$ is present in $\mathrm{C} 16: 1 \omega 7$, which is related to the high concentration of this FA in the diatom S. costatum (Table 2). When the diatom cells are present inside the sponge as intact cells, the ${ }^{13} \mathrm{C}$ enrichment of C16:1 107 will be higher inside the sponge as well. Figure $4 \mathrm{a}$ shows that after $8 \mathrm{~h}$ of feeding indeed the ${ }^{13} \mathrm{C}$ enrichment of 'sponge' FA resembled that of $S$. costatum. 
Within the first day, FA enrichment levels did not change drastically, but a rapid decrease of ${ }^{13} \mathrm{C}$ excess in diatom biomarkers was observed during the second day. Thus, the sponges either started to excrete the cells or to use the diatoms for their own metabolism for energy generation and build new biomass. These results confirm the results found by Schmidt (1970) as he found that feed particles were removed from the sponge body after $48 \mathrm{~h}$. In our study, we were able to detect ${ }^{13} \mathrm{C}$ enrichment in diatom FAs up to 10 days, indicating that it takes in the order of a week for sponges to process algal material after capture. Rapid collection of food followed by slow processes of algal material is an excellent strategy to survive in lowfood environments or when food supply is pulsed.

Several long-chain FAs were abundant in H. oculata and they were not present in S. costatum (Table 2). Although in their natural habitat, these long-chain fatty acids are not sponge-specific biomarkers, in this case where we feed with specifically label diatoms, label incorporation in these fatty acids must be due to sponge metabolism. Figure $4 \mathrm{~b}$ shows the incorporation of ${ }^{13} \mathrm{C}$ into these long-chain FAs. It is clear that ${ }^{13} \mathrm{C}$ incorporation in $\mathrm{C} 24: 1(17)$ started immediately, reached maximum levels at day one and then decreased gradually. The decrease of this intermediate compound was likely caused by the transformation to longer-chain FAs, like $C 26: 3(5,9,19)$ and $C 28: 3(5,9,21)$, which showed slower increase in label but incorporation continued up to the end of the experiment. Especially for $\mathrm{C} 26: 2(5,9)$ and $\mathrm{C} 28: 3(5,9,21),{ }^{13} \mathrm{C}$ enrichment was still increasing 3 weeks after labeling (Fig. 4b).

\section{Dysidea avara}

During the feeding of $D$. avara, we could not count the cell decrease in the water during incubations because of logistic restrictions, but we measured ${ }^{13} \mathrm{C}$ of particulate organic carbon in the water, which decreased from $9.4 \mu \mathrm{g} / \mathrm{l}$ after $1-\mathrm{h}$ feeding to $5.2 \mu \mathrm{g} / \mathrm{l}$ after 8 -h feeding. Moreover, $\delta^{13} \mathrm{C}$ values decreased from 383 to $262 \%$ during the same time interval, which means that the labeled cells were preferentially filtered from the water. After $8 \mathrm{~h}$, more than half of the added particles were still left, indicating that $D$. avara was less efficient than $H$. oculata in capturing particles, probably because $D$. avara filtered less water than $H$. oculata. The filtration rate found for D. avara was $0.851 \mathrm{~h} \mathrm{~h}^{-1}$ sponge $^{-1}$; this is somewhat low but still in the range as reported before (Ribes et al. 1999). The low filtration rate was most likely caused by the stress inherent to collection. Besides this, there could also be a seasonal effect as $H$. oculata were sampled in summer, whereas $D$. avara was sampled in January.

Figure 2 shows the total ${ }^{13} \mathrm{C}$ and the total fatty acid ${ }^{13} \mathrm{C}$ enrichment for both sponge species. Although ${ }^{13} \mathrm{C}$ acquisition was lower during the feeding period, retention of ${ }^{13} \mathrm{C}$
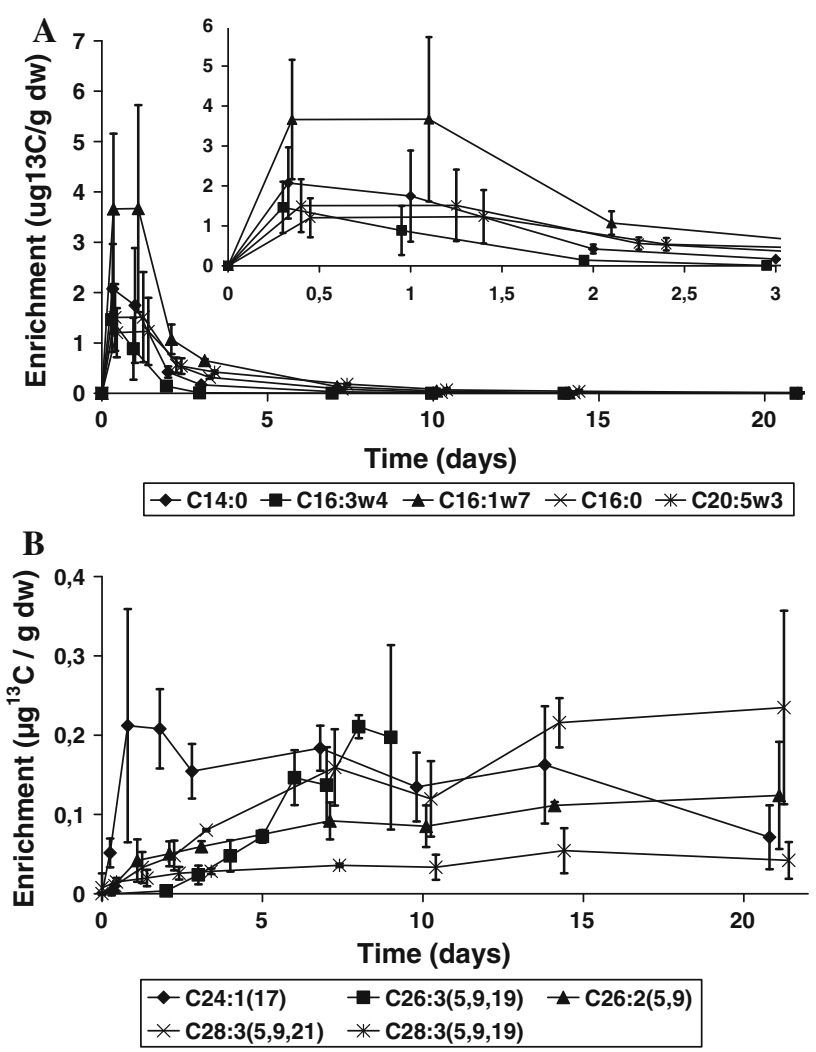

Fig. $4{ }^{13} \mathrm{C}$ Enrichment of feed fatty acids (a) and in high concentrated long-chain fatty acids (b) in Haliclona oculata expressed in $\mu \mathrm{g}$ ${ }^{13} \mathrm{C}$ in the specific FA per gram dry weight of sponge, the error bars show the standard deviation. The $x$-axis is slightly shifted to show the corresponding error bars

was higher in $D$. avara than in $H$. oculata. After 8 days, $67.7 \%$ of total ${ }^{13} \mathrm{C}$ excess and $46.7 \%$ of $\mathrm{FA}^{13} \mathrm{C}$ excess was still present inside. D. avara appears to keep the acquired carbon longer in its body than $H$. oculata, both in terms of total ${ }^{13} \mathrm{C}$ and $\mathrm{FA}{ }^{13} \mathrm{C}$. D. avara lives in a more oligotrophic environment (i.e. Mediterranean) than $H$. oculata (The Netherlands) and efficient retaining captured algae is a sensible strategy to survive in food depleted settings. Besides; Ribes et al. (1999) found that D. avara obtains $85 \%$ of its ingested carbon from the fraction smaller than $5 \mu \mathrm{m}$ and $15 \%$ from the fraction larger than $5 \mu \mathrm{m}$. Thus, the diatoms are not the main food for D. avara.

During the experiment with $D$. avara, some unexpected results appeared. Figure 5a shows that the highest ${ }^{13} \mathrm{C}$ enrichment of diatom biomarkers was found after 1 day for D. avara. After incubation of the sponge with label in the laboratory for $8 \mathrm{~h}$, they were placed back in the sea, but this could not be done immediately. As a consequence, label acquisition continued beyond $8 \mathrm{~h}$. Following an expected decrease during the second day and a sudden and unexpected increase occurred after 4 days, which can also be seen in Fig. 2. The increase can only be explained by cross-contamination from another in situ labeling 

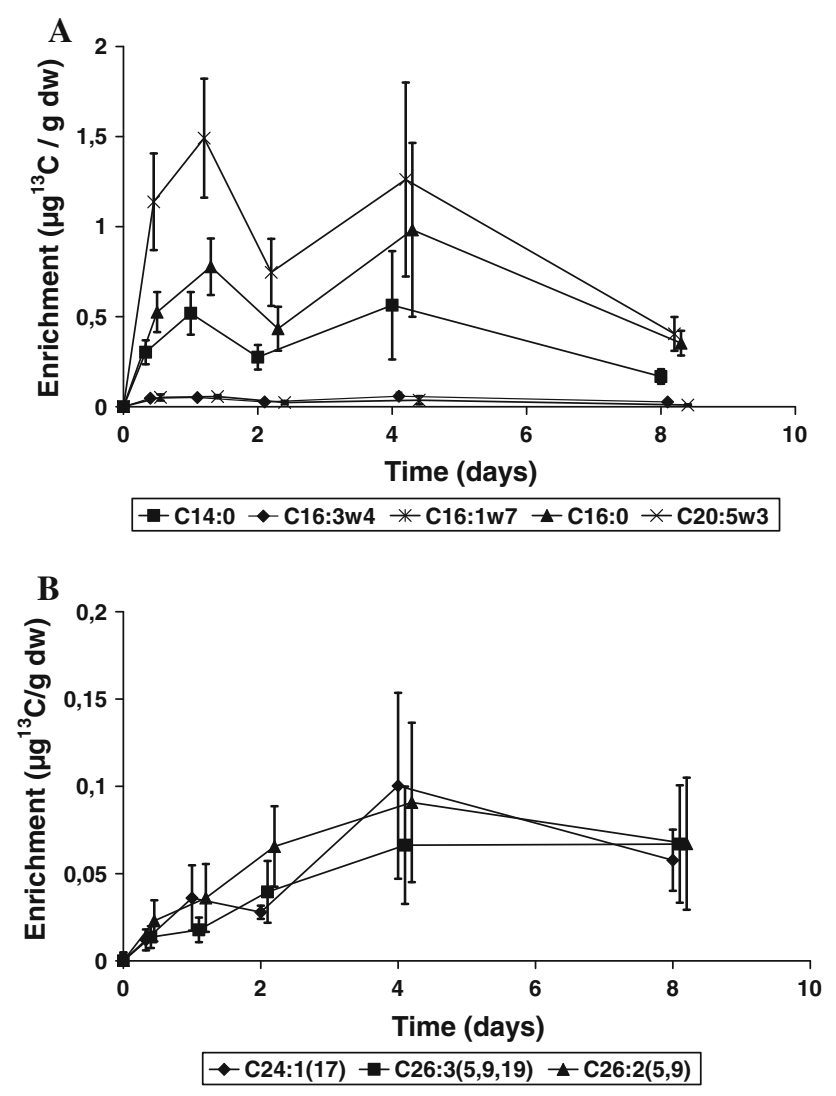

Fig. 5 Average ${ }^{13} \mathrm{C}$ enrichment of feed fatty acids (a) and in high concentrated long-chain fatty acids (b) in Dysidea avara, the error bars show standard deviation. The $x$-axis is slightly shifted to show the corresponding error bars

experiment done by us nearby. After 8 days, the enrichment levels of the diatom biomarkers decreased again but did not approach zero as expected. Another striking result is the low enrichment of two diatom FAs (Fig. 5a), as if during the culturing of the labeled cells these FAs were less formed and thus labeled.

In $D$. avara, less label was found in the long-chain sponge FAs (Fig. 5b), which is a result of the lower ${ }^{13} \mathrm{C}$ uptake (Fig. 2). Enrichment level of $\mathrm{C} 24$ and C26 were similar; however, C24:1(17) showed a similar trend as the diatom biomarkers, namely the decrease after 2 days with an increase again after 4 days (Fig. 5). C24:1(17), an intermediate compound, was apparently turned over faster than the other long-chain FA.

Increased metabolic rate due to damaging

\section{Filtration and respiration rate}

H. oculata and D. avara are two very different sponge species with a different structure. Due to the difference in sponge structure also different damaging strategies were used. For H. oculata, we used scissors to cut off all tips of each sponge specimen used. For D. avara, we scraped off part of the tissue of one half of a sponge, leaving the other half intact. After the experiment, we collected the damaged and non-damaged parts of each sponge specimen separately and analyzed them on ${ }^{13} \mathrm{C}$ content. For $H$. oculata, this was easier as the tips and rest of the body could easily be separated. For D. avara, this was less easy, because of the colonized organization it sometimes seemed that the damaged and healthy part started to act as two separate sponges. Consequently, it is difficult to compare the difference in damaged and non-damaged tissue of one sponge individual.

All sponges were fed with the same amount of ${ }^{13} \mathrm{C}$ labeled biomass $P$. tricornutum. For each sponge, we took a sample of water at the end of feeding from inside the experimental chamber, which was next tested on ${ }^{13} \mathrm{C}$ content to determine the amount of ${ }^{13} \mathrm{C}$ taken up by the sponge. We compared filter capacities of damaged sponges to that of the non-damaged sponges (Fig. 6). Figure 6 shows the ${ }^{13} \mathrm{C}$ fraction in atom\% in the SPM of the water inside the experimental chamber at the start and after 25 -min feeding. The starting value was the same for all experiments. A decrease in ${ }^{13} \mathrm{C}$ fraction means that the added diatoms are filtered preferentially over other carbon containing particles. Only for $D$. avara, the total carbon content was measured and actual filtration rates could be measured. This confirmed that a lower ${ }^{13} \mathrm{C}$ fraction in the water at the end of the experiment means a higher filtration rate. The decrease in enrichment after $25 \mathrm{~min}$ is the same for the non-damage and feed-first experiment as was

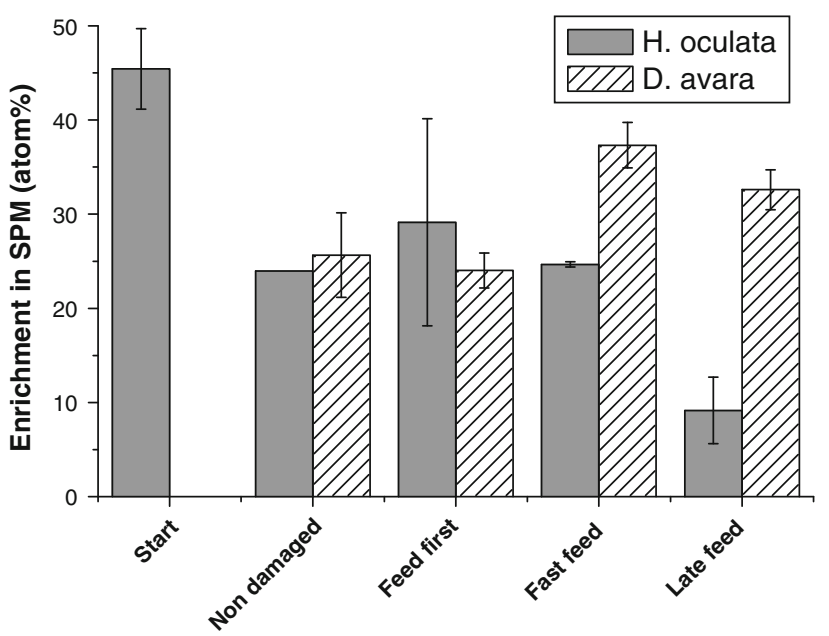

Fig. 6 Fraction at the start of feeding and after 25 min of feeding for the different approaches. The start concentration is the same for both sponges. Non-damage and feed-first are non-damaged sponges while feeding, fast feed means immediate feeding after damage and late feed means that after damage a lag time was taken into account of $6 \mathrm{~h}$ (H. oculata) or $24 \mathrm{~h}$ (D. avara) 
expected because both treatments mean the sponges are fed when not being damaged.

Directly after damage, $H$. oculata does not change filtration rate while $D$. avara immediately decreases filtration rate. After 6-h filtration rate for $H$. oculata increased to a higher value than the original value. D. avara responded faster than $H$. oculata to damage with a reduction of food uptake instead of an increase. Also at the late feed, still a reduction in food uptake was observed. However, for D. avara, late feeding occurred later (at $24 \mathrm{~h}$ ) than for H. oculata $(6 \mathrm{~h})$. We were forced to use these different time intervals for late feeding due to bad weather conditions in the case of D. avara. Apparently, the response of $H$. oculata after damage is to increase food uptake for wound healing, while most likely the reduction of food uptake by D. avara is caused by killing part of the sponge tissue, leaving only half of the sponge alive for filtering. Respiration rate was also measured during feeding for $\mathrm{H}$. oculata. Respiration rate immediately decreased after damage but was restored $6 \mathrm{~h}$ after damage (Fig. 7). The large increase in filtration rate $6 \mathrm{~h}$ after damage coincided with an increase of the respiration rate to the original level. The respiration rate measurements failed during the experiment with $D$. avara due to technical problems with the oxygen meters.

We only have respiration rate measurements for $H$. oculata, because the respiration rate measurements failed during the experiment with $D$. avara due to technical problems with the oxygen meters. Respiration rate for H. oculata immediately decreased after damage, but was restored $6 \mathrm{~h}$ after damage (Fig. 7). This only partly correlates with the filtration rate. The initial decrease in respiration due to damage was not accompanied with a decrease in filtration, which stayed the same. The following restoration of the respiration rate to the original level correlated with an increase in filtration rate.

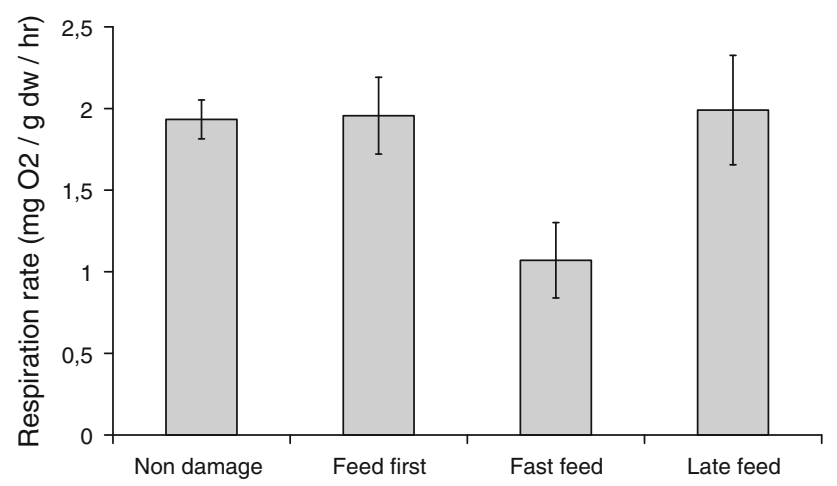

Fig. 7 Average respiration rate of $H$. oculata after different treatments

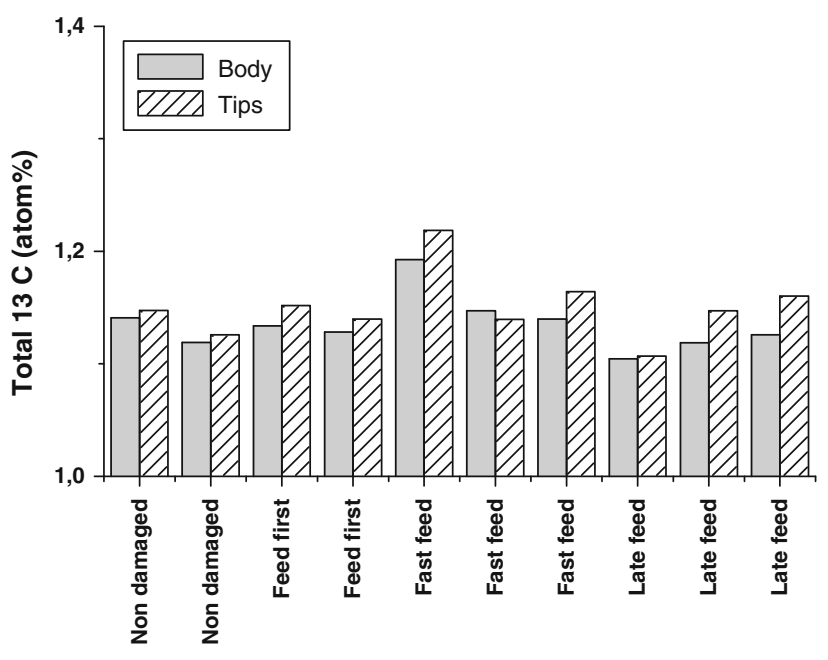

Fig. $8{ }^{13} \mathrm{C}$ content in each sponge separated for the damaged tips and non-damaged body for $H$. oculata

\section{${ }^{13}$ C label in whole sponges}

Despite clear differences in ${ }^{13} \mathrm{C}$ label uptake between damaged and non-damaged sponges, no significant differences in levels of ${ }^{13} \mathrm{C}$ label inside the sponges were found 1 week after feeding (Figs. 8, 9). From the sponge individuals, we collected the damaged and non-damaged tissue separately. For H. oculata, this was easier as we damaged the tips of the sponge-fingers simply by cutting them off. For D. avara, we split all sponges in half, where one half was damaged and the other half was left intact. $H$. oculata contained higher concentrations of ${ }^{13} \mathrm{C}$ label in the tips, both in the case of damaged and non-damaged sponges (Fig. 8). The damaged sponges had slightly more ${ }^{13} \mathrm{C}$ in the tips than the nondamaged sponges, but the difference was not significant. This indicates that the food uptake in the tips is higher than in the rest of the body and that this may increase upon damage. This increase seems to indicate that growth occurs at the tips and that the metabolic activity in the tips is higher than in the rest of the tissue. $H$. oculata has two outliers in ${ }^{13} \mathrm{C}$ uptake, the first fast feed sponge shows higher ${ }^{13} \mathrm{C}$ content than the other sponges and the first late feed sponge shows a lower ${ }^{13} \mathrm{C}$ content. The ${ }^{13} \mathrm{C}$ fraction for $D$. avara showed large variations between the three individuals. No systematic difference was found between damaged and non-damaged parts for D. avara (Fig. 9). This could be explained by the fact that apparently $D$. avara lives more like colonies, and when part of the sponge is damaged, it seems to be left to die and the intact part is the part growing on.

\section{${ }^{13} \mathrm{C}$ label in specific fatty acids}

Whether ${ }^{13} \mathrm{C}$ label is present as algal cells or metabolized algal biomass can be seen in the specific fatty acid content. 


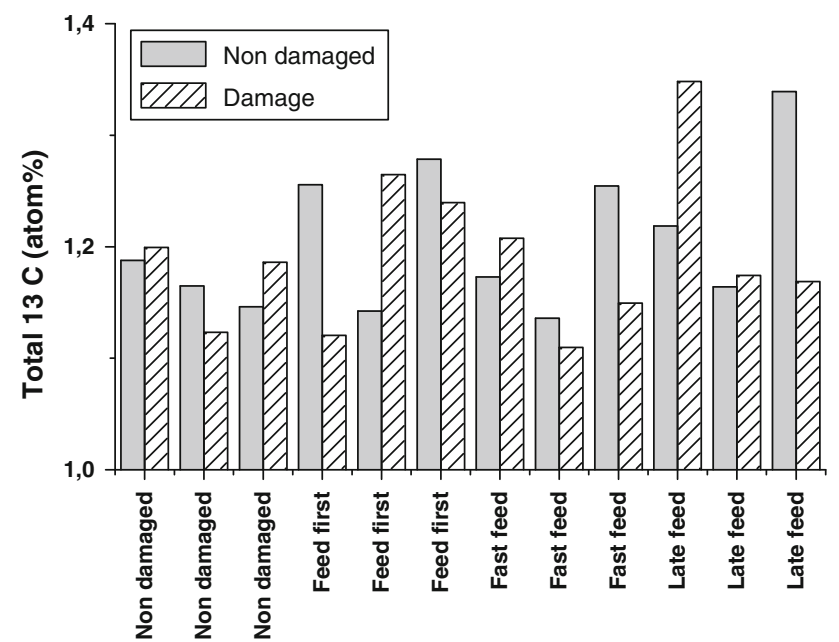

Fig. $9{ }^{13} \mathrm{C}$ content in each sponge separated for the damaged and non-damaged part for D. avara

The fatty acid (FA) C16:0 is a biomarker for diatoms (Dunstan et al. 1994). This biomarker was still present in the sponge body after 7 days (Fig. 10). For H. oculata, more ${ }^{13} \mathrm{C}$ label was present in this $\mathrm{FA}$ in the tips of the damaged sponges, in contrast to the non-damaged sponges where this was not the case. This confirms the finding that damaged tips took up more ${ }^{13} \mathrm{C}$ label (Fig. 8). The FA $\mathrm{C} 26: 2(5,9)$ is very abundant in both sponges and nonexistent in P. tricornutum (data not shown). In the tips of both damaged and non-damaged $H$. oculata, more enrichment in this sponge biomarker was observed than in the rest of the body (Fig. 10). The difference between tips and body was larger for damaged sponges with the exception of one individual at the late feed. Apparently, more ${ }^{13} \mathrm{C}$ label was converted in the damaged tips when compared to nondamaged tips. This is in accordance with the fact that H. oculata grows at the tips (Kaandorp 1991), which leads to more ${ }^{13} \mathrm{C}$ label in the tips. Regeneration is mostly found to be a faster process in sponges than normal growth (Ayling 1983; De Caralt et al. 2003, 2008; Duckworth 2003), which is confirmed here by the higher enrichment found in the tips of damaged sponges. For D. avara, the variation in ${ }^{13} \mathrm{C}$ fraction is again very high, which makes it impossible to see significant differences between damaged and nondamaged parts of the sponges and between damaged and non-damaged sponges. D. avara shows the same trend in the food and sponge FAs as for the total amount of ${ }^{13} \mathrm{C}$ in the sponges (Fig. 10). Remarkable for D. avara was that the food biomarkers were still highly present after 1 week, while the sponge components were not that high enriched. For $H$. oculata, this was just the other way around, where higher levels of enrichment were found for the sponge component and not for the food components. The latter was also found before, where less ${ }^{13} \mathrm{C}$ label was found in the larger FAs in D. avara than in $H$. oculata. However, the absolute values of enrichment did not differ too much in the sponge FAs for both $H$. oculata and D. avara. Apparently, the food FAs are metabolized slower or stored in D. avara.

\section{Conclusion}

Two sponge species (Haliclona oculata and Dysidea avara) fed with ${ }^{13} \mathrm{C}$-labeled diatoms became strongly enriched within $8 \mathrm{~h}$ after taking up the labeled cells. The sponge remained strongly labeled during the first 2-3 days because diatoms, as inferred from intact diatom fatty acids, were still present. However, 10 days after labeling, diatomspecific-labeled FA could not be detected anymore indicating that diatom cells were either excreted or converted. Sponge-specific fatty acids were produced from day one onwards and 3 weeks after labeling ${ }^{13} \mathrm{C}$ levels still increased in the longer-chain fatty acids (FAs) in Haliclona oculata. Thus, food particles taken up at a certain moment are still being processed 3 weeks later.

Both sponge species responded quickly to damage. Immediately after damage $H$. oculata respired less, but
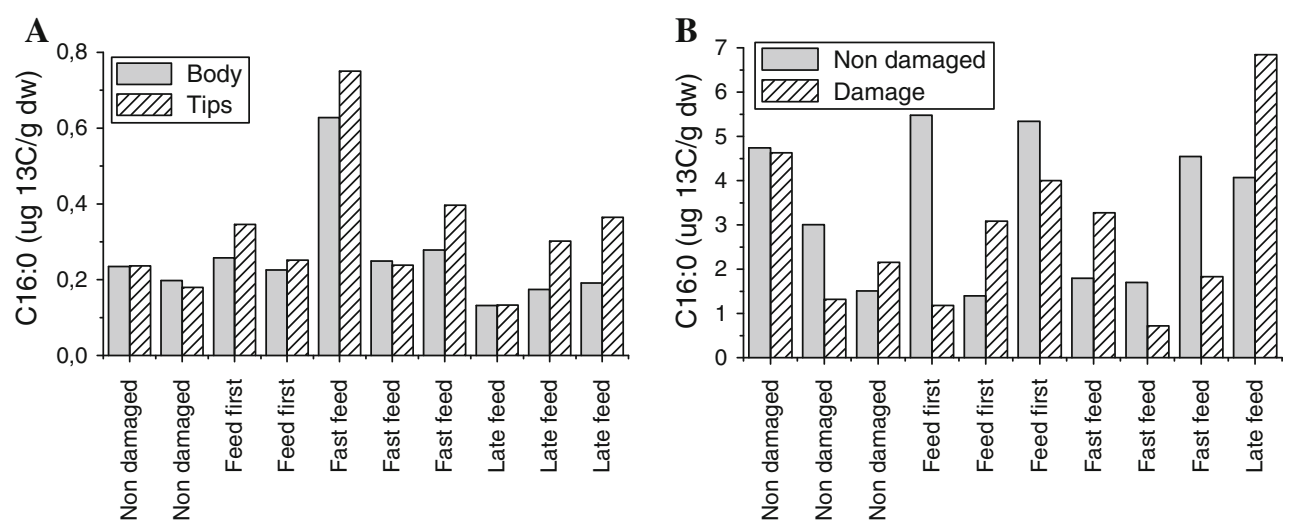

Fig. $10{ }^{13} \mathrm{C}$ content in $\mathrm{C} 16: 0$ in each sponge separated for the damaged and non-damaged part for H. oculata (a) D. avara (b) 
respiration rate recovered to the original rates within $6 \mathrm{~h}$. Filtration rate initially stayed the same but increased to a higher level within $6 \mathrm{~h}$ after damage. In contrast, D. avara immediately decreased filtration rate after damage, which was partly but not fully restored 1 day later. One week after labeling relatively less ${ }^{13} \mathrm{C}$-labeled algal biomarkers were found in $\mathrm{H}$. oculata compared to ${ }^{13} \mathrm{C}$ label in sponge biomarkers. $D$. avara had comparable enrichment in sponge biomarkers but contained clearly more algal biomarkers indicating that $D$. avara either stored algal components and/or respired them less fast than $H$. oculata, whereas assimilation into biomass was comparable.

Damaged and non-damaged tissue was collected separately. In $\mathrm{H}$. oculata, a higher fraction of ${ }^{13} \mathrm{C}$ label was found in the tips of both damaged and non-damaged sponges, indicating that growth rate is higher in the tips. The sponge biomarkers were higher enriched in the tips of the damaged sponges compared to the non-damaged sponges, indicating a higher growth and metabolic rate in the tips after damage. For D. avara, large variation in levels of ${ }^{13} \mathrm{C}$ label was found in healthy and damaged tissue, and significant differences were not found.

The differences found between the sponges can be explained by the different growth forms of the two sponge species. H. oculata is a finger sponge and grows mostly at the tips. D. avara is an encrusting sponge that lives more like colonies and when part of the sponge is damaged it seems to be left to die and the intact part is the part that continues to grow.

Acknowledgments This study was funded by NWO-ALW (814.02.010). We thank the Waterboard Zeeuwse Eilanden and the province of Zeeland for issuing the necessary permits, and Maria Uriz for providing us with the permits to collect sponge specimens in name of CSIC-CEAB. We are grateful to A. Kliphuis, J. Lindenbergh, B. van Vark, E. van Vark, P. Lamers, and A. Bal for helping with placing the platform and the monitoring. Thanks to the Netherlands institute for ecology for providing equipment for the extraction and analysis of the fatty acids and M. Houtekamer and P. van Breugel for their analytical assistance.

Open Access This article is distributed under the terms of the Creative Commons Attribution Noncommercial License which permits any noncommercial use, distribution, and reproduction in any medium, provided the original author(s) and source are credited.

\section{References}

Ayling AL (1983) Growth and regeneration rates in thinly encrusting demospongiae from temperate waters. Biol Bull 165:343-352

Bergquist PR (1978) Sponges. Hutchinson \& Co Ltd, London

Bergquist PR, Lawson MP, Lavis A, Cambie RC (1984) Fatty acid composition and the classification of the porifera. Biochem Syst Ecol 12:63-84

Boschker HTS, Middelburg JJ (2002) Stable isotopes and biomarkers in microbial ecology. FEMS microbiology 40:85-95
Boschker HTS, de Brouwer JFC, Cappenberg TE (1999) The contribution of macrophyte-derived organic matter to microbial biomass in salt-marsh sediments: Stable carbon isotope analysis of microbial biomarkers. Limnol Oceanogr 44: 309-319

Christie WW, Brechany EY, Stefanov K, Popov S (1992) The fatty acids of the sponge Dysidea fragilis from the Black Sea. Lipids 27:640-644

De Caralt S, Agell G, Uriz MJ (2003) Long-term culture of sponge explants: conditions enhancing survival and growth, and assessment of bioactivity. Biomol Eng 20:339-347

De Caralt S, Uriz MJ, Wijffels RH (2008) Grazing, differential sizeclass dynamics and survival of the Mediterranean sponge Corticium candelabrum. Mar Ecol Prog Ser 360:97-106

De Goey JM, Moodley L, Houtekamer M, Carballeira NM, van Duyl FC (2008) Tracing 13C-enriched dissolved and particulate organic carbon in the bacteriacontaining coral reef sponge Halisarca caerulea: evidence for DOM feeding. Limnol Oceanogr 53:1376-1386

Djerassi C, Lam W (1991) Sponge phospholipids. Acc Chem Res 24:69-75

Duckworth AR (2003) Effect of wound size on the growth and regeneration of two temperate subtidal sponges. J Exp Mar Biol Ecol 287:139-153

Dunstan GA, Volkman JK, Barrett SM, Leroi JM, Jeffrey SW (1994) Essential polyunsaturated fatty acids from 14 species of diatom (Bacillariophyceae). Phytochemistry 35:155-161

Hahn S, Stoilov TB, Ha TBT, Readerstorff D, Doss GA, Li H, Djerassi C (1988) Biosyntethic studies of marine lipids. 17. The course of chain elongation and desaturation in long-chain fatty acids. J Am Chem Soc 110:8117-8124

Hatcher A (1989) RQ of benthic marine invertebrates. Mar Biol 102:445-452

Kaandorp JA (1991) Modelling growth forms of the sponge Haliclona oculata (Porifera, Demospongiae) using fractal techniques. Mar Biol 110:203-215

Kharlamenko VI, Kiyashko SI, Rod'kina SA, Imbs AB (2008) Determination of food sources of marine invertebrates from a subtidal sand communtiy using analyses of fatty acids and stable isotopes. Russ J Mar Biol 34:101-109

Koopmans M (2009) Growth and metabolism of sponges. Bioprocess Engineering, Wageningen, pp 61-80. ISBN: 978-90-8585441-8

Koopmans M, Wijffels RH (2008) Seasonal growth rate of the sponge Haliclona oculata (demospongiae: Haplosclerida). Mar Biotechnol 10:502-510

Koopmans M, Martens D, Wijffels RH (2009) Growth efficiency and carbon balance for Haliclona oculata. Mar Biotechnol (in press)

Litchfield C, Greenberg AJ, Noto G, Morales RW (1976) Unusually high levels of C24-C30 fatty acids in sponges of the class demospongiae. Lipids 11:567-570

Middelburg JJ, Barranguet C, Boschker HTS, Hesse C, Moens T, Heip CHR (2000) The fate of intertidal microphytobenthos carbon: an in situ 13C labelling study. Limnol Oceanogr 45:1224-1234

Nechev J, Christie WW, Robaina R, de Diego F, Popov S, Stefanov K (2002) Lipid composition of the sponge verongida aerophoba from the Canary Islands. Eur J Lipid Sci Technol 104:800-807

Nieuwenhuize J, Maas YEM, Middelburg JJ (1994) Rapid analysis of organic carbon and nitrogen in particulate materials. Mar Chem 45:217-224

Raederstorff D, Shu AYL, Thompson JE, Djerassi C (1987) Biosyntethic studies of marine lipids. 111 Synthesis, biosynthesis, and absolute configuration of the internally branched demospongic acid 22-Methyl-5, 9-octacosadienoic acid. J Org Chem 52:2337-2346 
Ribes M, Coma R, Gili JM (1999) Natural diet and grazing rate of the temperate sponge Dysidea avara (Demospongiae, Dendroceratida) throughout an annual cycle. Mar Ecol Prog Ser 176:179-190

Rod'kina SA (2005) Fatty acids and other lipids of Marine sponges. Russ J Mar Biol 31:S49-S60

Rod'kina SA, Latyshev NA, Imbs AB (2003) Fatty acids from the sea of Japan Sponge Halichondria panicea. Russ J Bioorg Chem 29:382-386

Schmidt I (1970) Phagoeytosis and pinocytosis in spongillids. Z vergl Physiologie 66:398-420
Thiel V, Jenisch A, Wörheide G, Löwenberg A, Reitner J, Mechaelis W (1999) Mid-chain branched alkanoic acids from "living fossil" demosponges: a link to ancient sedimentary lipids? Org Geochem 30:1-14

Uriz MJ, Rosell D, Martin D (1992) The sponge population of the Cabrera archipelago (Balearic islands): characteristics, distribution, and abundance of the most representative species. Mar Ecol 13:101-117 